\title{
Redesigning Organizational Structure as a Respond to the Uncertainty Environment in the Newspaper Company
}

\author{
Muhammad Ridwan Arif*, Asty Almaida** \\ * President Director, PT.Media Fajar (Fajar Group), lecturer at Ujung Pandang State Polytechnic \\ ** Department of Management, Faculty of Economics and Business, Universitas Hasanuddin, \\ Makassar-Indonesia
}

\begin{abstract}
The objective of this paper is to identify the contingency factors in respond to environmental changing in designing the organizational structure for newspaper company. The current environment exist as the industry faces an uncertain future because of stagnant markets, increasing competition from other media for audience and attention, use by progressively smaller portions of the populations, and changes in advertiser media choice. Based on the literature review, by employing the contingency perspectives, the organizational size, effective strategy, and adoption the high technology will influence the capability of organization to respond the environmental changing that in turn can strengthening it's competitive advantage and innovation in uncertainty environment.
\end{abstract}

Keywords: contigency, environmental changing, effective strategy, newspaper, uncertainty

\section{Introduction}

The latest survey in USA reveals that the global newspaper industry is in "a stae of turmoil", generally experienced with downturn in financial performance, slowing down the profitability in the last five years, and even, in bankruptcy situation. People in Detroit has enjoyed three strong daily newspapers over decades, now only one newspaper served the community and it is delivered on only three days a week. It is also happened in Denver, the people in the state used to have two big newspaper, not so today, it has only one. Generally, newspaper circulation in USA have been declining for years by around 2 percent per year, and the percentage has been growing in the last couple of years and is now in the range of 4 $-5 \%$ per year (Fabian, 2009).
The main cause of the above problem suffered by the companies is the migration from the print medium to the electric medium. There are several factors contribute to above conditions, such as rapidly developing technology, changing consumer habits and other environmental modifications that started to dissolve newspapers' competitive advantage The current environment exist as the American newspaper industry faces an uncertain future because of stagnant markets, increasing competition from other media for audience and attention, use by progressively smaller portions of the populations, and changes in advertiser media choice. The companies encounter advertising revenue plummet, internet penetration increase and new technologies interfere the marketplace. (Picard,,2004). 
Under these circumstances, that can be identified as environmental change in the specific market, those who responsible for the governance and operations of newspaper companies need to reconsider their current business strategies. The environmental changing requires the organization to analyze the organizational matter as a whole to reinvent the suitable strategy that fit to the current and future environment.

Organizational change is a complex activity that requires structure and process factors can differentiate one organization with other organization that influenced by the environmental complexity and degree of change (uncertainty condition). Moreover; the effective organizational performance is determined by the fit between an organizational social structure and its environment. In other words, the most successful organization are those where the degree of differentiation and the means of integration match the demands of the environment. (Donalson ,1996).

Therefore; we would propose the

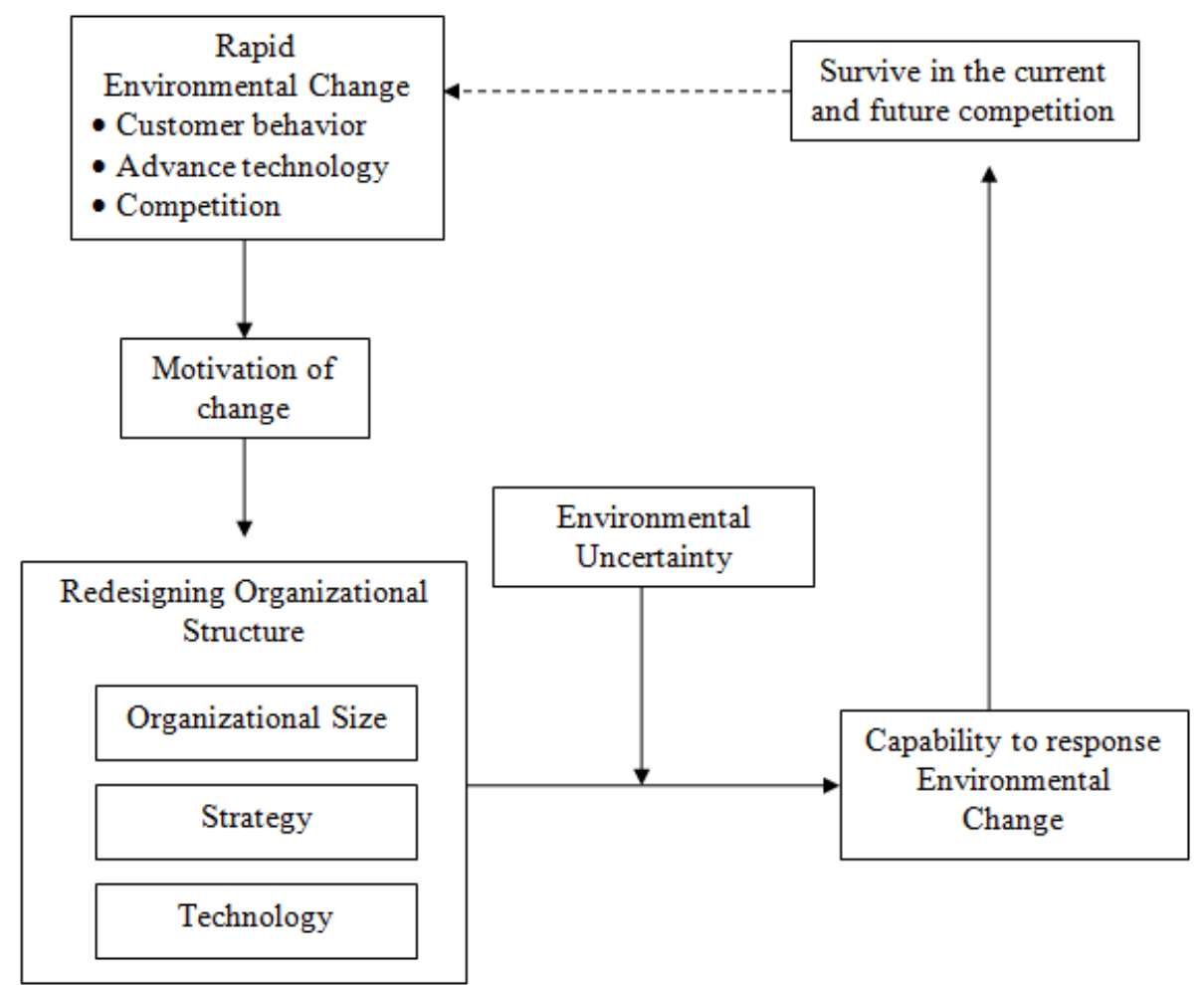

Figure 1 ConceptualFramework

to be effective. It is commonly known nowadays that change is a constant. The globalization of market, rapid advancements in new technology, higher level of competition, increasing focus on costs and cost management and the inevitable excess of demand over supply in terms of competent individuals contribute to the drive for change within contemporary organizations. (Victor and Francheise 2002).

There are several contingency factors that characterize organization i.e.; strategy, size; uncertainty and technology. The contingency factors in analyzing the newspaper company organization relate to its structure design as a response action toward the uncertainty external condition. The conceptual framework of analysis is described in Figure 1. The framework is cyclical as the process of the environmental change, organizational response and structural redesigning has been continuously developing even in the future.

\section{Contingency Perspective}

Contingency theory claim that the dimensions of organizational structures 
relate to each other differently depending upon the environment the organizations faces and other aspects of the organizations such as its technology; size; and strategy. By analyzing relationship between environmental change (uncertainty) and structural dimensions; the theorist believe they can offer recipes for the best organizational structures. (Hatch, 2002)

\section{Environmental Uncertainty in the declining stage}

Is the newspaper industry are in the decline stages in the business life cycle? Declining industries are those that have experienced an absolute decline in unit sales over a sustained period. (Porter , 1998.. pp. 254). The concept of Porter's business cycle is deployed to describe the condition take place in the newspaper industry.

The degree of demand uncertainty is one of the most persuasive factors in declining stages. When management confident that demand will renew, they will probably try to stay on their position. In adverse, when they are confident that the demand of the industry will continue to decline, the reduction of capacity is more likely to be the right choice (Porter, 1998).

The company should accurately detect the attitude for the various market segments of their business and analyzed where enduring demand might exist. Demand could endure where products requested by customers who would switch products with great reluctance or only if use the substitute product were clearly more desirable. Identification of niches market is important, but they do not exist in all declining business. The favorable for continued to compete in specific industries rely on three consideration, i.e. the sensitive price to demand; the certainty of replacements product; and the presence of loyal customers, (Harrigan, 1980)

The newspaper industry suffering the "disruptive innovator attack" from many other type of media that undercutting the traditional newspaper business model. In fact, disruptive innovation has affected the newspaper industry for decades, - network news, cable news, and now online news.
The effect of the disruptive innovation in news influences the advertisement market. Classified advertising was once an extraordinary profitable, nearly exclusive, for newspaper. However, the other type of media offers a free classified service that is flourishing and expanding in many major cities in the world. (Sterling2008).

Two important changes in the business environment of newspaper organization have contributed to the loss of unique status on the part of the news organization. First, changes in communication technology have altered the way individuals get information and affected the ability of different entities to provide information. Second, is the communities have become more diverse so that a one size fits all model does not work the way it used to for readers and advertisers. In general, newspaper companies failed to respond to either of these changes (Sullivan, 2006).

\section{Organizational size}

Size of the organization refers to the number of employees in the organization that one of the dimensions of organizational social structure. The size of organization perceived as a factor affecting structure, the larger the organization the greater the degree of specialization and centralization. Specialization and centralization are two elements that can not be separated. Centralization affects the participation level of organization levels, communication pattern among the organizational elements, and coordination matters. (Hatch, 2002).

In a centralized organization, final decisions are made at top level of management; and unquestioning acceptance of top level decision is expected. As a result, it tends to be a minimum participation from lower level member. Opposite with former type of organization, decentralized organization encourage participation of lower level members in decision making process.

Moreover, centralized organization is quicker to respond to the dictates of higher authority because of the relative efficiency of communication compared with the 
decentralized ones. However when such organization are large, the respond tend to be slower due to bottleneck decision. Therefore most studies suggest that large organization indicate negative relationship between formalization and centralization. Therefore it can be trade off centralization for formalization because rules and procedures direct subordinates to make same decision their managers would make.

There are some studies about the role of size and structure in the management of change. One perspective contends that formalization and standardization reduce inertia, signifying a negative relationship between size and adaptation (e.g. Hannan and Freeman, 1984; Kelly and Amburgey, 1991). Haverman (1993) stated that the relationship between organizational size and change may depend on contextual factors such as environmental turbulence or change scope.

Mathews W. Ford (2009) evaluates competing views of whether organization size creates conditions of rigidity or fluidity with respect to adaptation and change. His study empirically compares processes used to implement planned change and their associated outcomes in small and large organizations. Results indicated that small organizations employed significantly lower levels of refreezing activities and realized lower levels of implementation success relative to large organizations.

However, other empirical study indicate that small firms are significantly more productive but also more risky than their large counterparts. The estimation results imply that the notion of a trade-off between flexibility and efficiency be adjusted for the dimension of risk. Small firms facing market uncertainties, capital constraints and other challenges undertake actions that make them more efficient than large firms but is achieved at the cost of increasing their riskiness (Dhawan, 2001).

Media industry including newspaper company have a high degree of specialization in organizational structure and the barriers between personal and informative interests are, somehow, fragile. Organizational size has been a less reliable determinant of design differences.
However some the latest study reveal that the number of graphics (quality) throughout the entire paper and in nonnews sections correlate positively with the size of staff in the organization (Nayak, 2009). The other scholar stated that design quality of newspaper is more greatly determined by the organizational size such as level of resources and degree of specialized expertise ( Lowrey ,2003). As the variety of business segments grows, the range of expertise needed in an effective board expands, potentially impacting the size and range of specialties required

In summary, the organizational size affects the capability of organization to respond the external environment such as competition in design. As the different product everyday, Newspaper industry competition is very rapid change that one organization must be quickly to respond in day by day pattern, such as the news content, interesting headline, design and the other management service. The rapid response of the organization may be influenced also by the degree of specialization and centralization. The organizational hierarchy affects the speed of decision making in product design, therefore, it should have the flexible, rapid response and simple characters. The head of editor in the organization also take an important role in designing the news content and layout. He/she should have the multiple perspectives about the content, that can be effectively absorb by a large varieties type of readers (customer).

\section{Strategy}

The second component of social structure of organization is the strategy. In order to survive in a rapidly changing environment, firms have to consistently use various types and levels of strategies to become more competitive.. Contigency theorists focusing on the environment and business-level strategy assert that firms that are able to adapt successfully to their environments by aligning their strategies with environmental requirements will achieve higher levels of performance than will firms that do not achieve such an alignment. Their concern with relationships between managerial 
characteristics (demographic characteristics, traits, or experience), strategy, and organizational performance argue that successful implementation of a particular strategy requires a CEO with the appropriate functional or industry experience, demographic characteristics, or leadership traits. And, finally, contingency theory suggests that scanning efforts should vary depending on environmental conditions encountered. In practice, organization regularly needed to evaluate how well the strengths and weaknesses of the existing structure match with the intended strategy and the potential opportunities and threats in the current and future environment.

Similar with the other organization, corporate strategy in media firm influences the legal framework and the corporate governance structure that relate to organizational change. Victor and Franckeiss (2002) argues that the organizational change is a complex activity that requires structure and process to be effective. Organizational change cannot be easily defined, therefore, need to be managed proactively and even need to be responsive to changing contingent circumstances. The structure and process needs to focus on all aspects of the change management model from developing the strategy through to operational implementation and evaluation. Lack of cohesion and alignment through this process will result in change programs not being optimally devised or implemented.

Furthermore, they explained that there are four principal enabling strategies that promote the alignment to achieve constancy of purposes and consistency of approach.

1. Resourcing strategy, concern with the design and structure of the business, the manner of process through which employees are recruited and the deployment of appropriate retention strategies; the training and development philosophy and practice, and the manner in which succession is managed.

2. Performance management strategy, relate to all activities and processes that ensure the strategic and operational business objectives are achieved. All elements within organization well understand their role and their requirements in conducting their functions.

3. Reward strategy, involve the pay structure and the composition and deployments of benefit packages and the bonus schemes.

4. Communication strategy, involve the manner the elements of organization interact, especially with the employees. Effective communication is clearly critical determinants of the change process and managing change is competence at every level of the organization.

These enabling strategies offer the bridge between the overall business vision and day-to-day management and operations of the business.

Other organizational experts proposed the strategic approach in designing the organizational strategy relate to competitive advantage. Resources based View (RBV) defined as the firm ability to integrate, build, and reconfigure internal and external competence to address rapidly changing environments. The RBV suggests a resource must be rare, valuable, inimitable and unique to the company's other resources (Barney, 1991).

It deploys the internal analysis in evaluating the strength and weaknesses of organization that generate the resources based model. In another part, the approach set up the external analysis in evaluating the opportunities and threats generating environmental models of competitive advantage. Competitive advantages are achieved when a firm is mplementing a value creating strategy that is not being simultaneously implemented by any current or potential competitors. (Barney 1991).

The relationship between corporate governance and corporate strategy in media company elaborated in Gerum and Stieglitz (2005) . The corporate governance system of the individual firm largely follows the selected corporate strategy. 
Technically the system provides the framework for formulating corporate strategic and certainly does influence the strategic decision making process. The study proposed the reinforcement of strategic control supervisory board in implementation of strategic management in media firm in assuring that the chosen strategy are continuously being evaluated and match with the current and future situation. It is logically and effectively true as the board as an integral part of the paper of average quality, with contend intended for mass audiences. Such strategies can be categorized as cost and price competition strategies. Other company may select a quality management strategy that is designed to generate the benefit value over time by saving money though attempts to keep quality at a level meets but does not exceed reader expectations.

Other strategy can typically used by who take a long term view toward maximizing

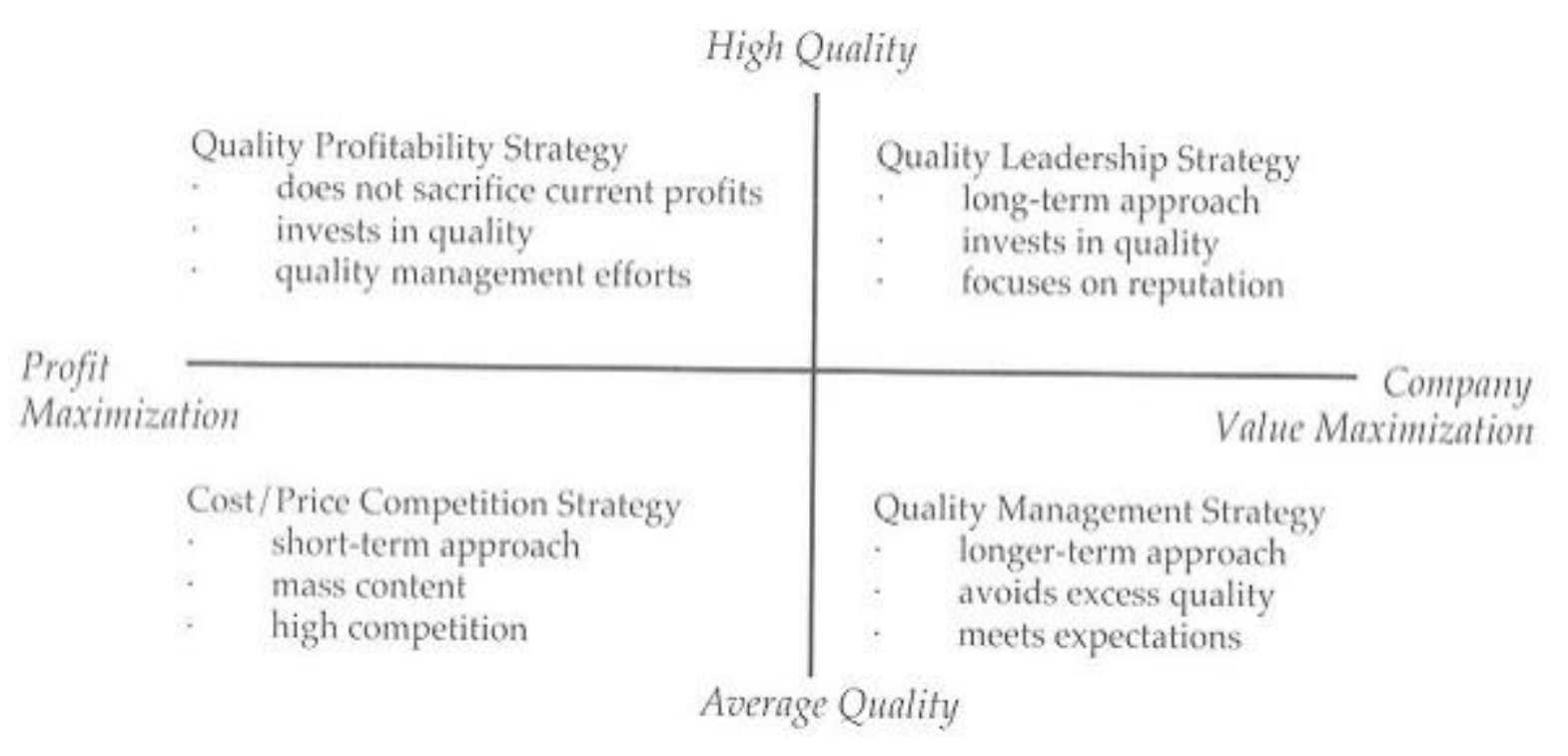

Figure 2 Strategic Choice Involving Quality and Performance

strategic control process within the firm.

It must be recognized that quality (in terms if overall aspect in newspaper product) and company performance are related (Picard 2004). The relationship between quality and performance graphically described as Figure 2. The figure shows four major strategies for newspaper publisher to follow. The quality choices are in between average quality and excellent quality/ not between poor and high quality as poor quality represent the condition that the readers will abandon the paper. Another axis represent two major commercial performance commonly adopted in newspaper companies/ profit maximization and company value maximization.

The company tend to maximize a newspaper's profit, by keeping cost low or encourage higher revenue, can provide a the value of their firms/ being seen as an excellent paper in terms of content quality and as having significant social and political influence. By selecting this strategy/the firm sacrifice some short term profits to maximize company value.

Other publisher can use a quality profitability strategy that is design to produce a high or moderate quality newspaper but does not sacrifice profitability through excess quality and engages in strategies to improve and manage such quality.

Bad practice experienced in one of the largest media company in Canada, Hollinger.Inc, showed a US\$73.4 million loss for the year 2005 in its financial report. It is revealed that the main cause of this condition as the management disregard for corporate governance that affects the overall strategy in the firm, that 
in turn weakened its competitive advantage in the Canadian newspaper industry. (Edge, 2005).

\section{Technology}

Technology is defined as means organizations use to convert raw material inputs into finished outputs regardless of whether the output is product or service. Contingency theory show that different technology types suit different environments, require different social structure and affect human action differently (Hatch 2002). The terminology of technology has many varieties of terms depend on the context and level of analysis. In analyzing the organization, modernist perspectives has three definitions of technology, i.e. core technology-high technology- service technology. Core technology means the transformation processes directly involved in producing the products and services. High technology is used when described different aspects of computer-based technologies. Services technology is defined of three main characteristics-as consumed as they are produced/are intangible/ and cannot be stored in inventory.

Technology term typically used in organization study relates to three elements:

1. objects (products, services, and tools and equipment) ;

2. task activities or processes

3. knowledge needed to develop and apply equipment, tool and method to produce a particular product or service.

Information technology is evolving rapidly, becoming wide spread and an integral part of nearly every part of today's organizations. Technology is being used to increase sales, manage operations, produce products and services, manage projects, and improve business processes. Today, networking and communications technologies, such as desktop publishing, e-mail, mobile phones, laptops, workstations, PDAs and networking hardware and software, are extensively used in organizations, as well as various types of software and solutions to support business functions, like scheduling, planning, budgeting, sales, production, and human resources.

Studying about technology in organization commonly raise an issue that how organization change their organization structures in response to a major technology innovation in specific industries or how this change in information technology may change the formal and informal organizational structures (Russel, 1999). Therefore the issue raise in this paper is how organization responds the market changes in term of advance technology utilization in media industry, especially in newspaper company.

Technology are becoming one of the primary factors for survival of most organizations, especially in media industry, as well as a source of competitive advantage for some, which makes technology investment decisions critical for organizations

The division of labor is increasingly important in the media industry as the industry is changing rapidly from being a traditional analog business to being in a completely digital environment. Staying ahead in technology and having the right expertise are vital in order to be competitive today (Sherburne, 2006).

The media industry has been evolving and is advancing technologically. The industry is moving rapidly into to an environment of complete digitization and automation, as evidenced by the fact that technologies supporting synergy and innovation are made use of in the various segments of the industry. The industry is transitioning into a multimedia industry where printing will be among a set of different segments (Romano, 2004).

Internet technology affects the newspaper company performance, as news does not only circulate by the printing paper, but also distribute via internet. Moreover, since newspapers can be read on the Internet, and the news is available on mobile phones. This can reasonably expect mobile audiences to present a large potential market. About one in three newspaper site users have read headlines on mobile devices, $11 \%$ have used a mobile 
or wireless "hot spot" to access a newspaper site; newspaper site users are twice as likely as non-users to be interested in receiving news on a portable device and twice as likely to have shopped using the device (online newspaper model).

In summary, publishing company cannot disregard the advance technology (high technology) in delivering their product to the customers. Technology can facilitate the rapid response of the organization toward rapid change of external situation, high-level competition and market behavior.

\section{Conclusion}

Declining advertisement revenue has severely impacted the newspaper industry in the present economic downturn, but it is an opportunity for the newspapers to transform. Rupert Murdoch dismissed the opinion that newspaper industry is dying breed, but the ideas of some editor and journalists were obsolete in the digital age (Breitbart.com). while the printed versions of some newspaper will lose circulation, there would be gains in other areas such as websites and emails delivering customized news and advertising.

Newspaper company cannot disregard the advance technology (high technology) in delivering their product to the customers. Technology can facilitate the rapid response of the organization toward rapid change of external situation, highlevel competition and market behavior. Management should reevaluate the strategy that used in the current situation, wheteher fit to the current and future environment. There are many alternatives strategy that can be deploy that generated from management thought including the strategy to adjust the organizational size and hierarchy.

\section{Reference}

Amburgey, Terry L; Kelly, Dawn; Barnett, William P (1993) .,Resetting the clock: The dynamics of organizational change., Administrative Science Quarterly; Mar 1993; 38, 1; ABI/INFORM Global pg. 51.
An, S and Jin., H.S., (2004)., Interlocking of Newspaper Companies with Financial Institutions and Leading Advertisers., J\&MC Quarterly., Vol. 81, No. 3 Autumn 2004., pp. 578-600..

Bardoel. Jo., (2002), The Internet, Journalism And Public Communications Policies., The International Journal for Communication Studies., 2002., Vol. 64(5) pp. 501-511.

Barney., J., (1991)., Firm Resources and Sustained Competitive Advantage., Journal of Management., Mar 1991., 17.1. pp. 99-120.

Carter., N., M., (1984)., Computerization As A Predominate Technology: Its Influence On The Structure of Newspaper Organizations.,Academy of Management Journal (pre-1986); Jun 1984; 27, 000002; ABI/INFORM Global pg. 247.

Dhawan., R., (2001)., Firm size and productivity differential: Theory and evidence from a panel of US firms.,. Journal of Economic Behavior \& Organization. Amsterdam: Mar 2001. Vol. 44, Iss. 3; pg. 269).

Edge., M (2005) ., The Pain of the Obdurate Rump: Conrad Black and 165 the Flouting of Corporate Governance., Corporate Governance of Media Companies., Media Management and Transformation Centre Jönköping International Business School., pp 165.

Fabian, N,. (2009), From the World of Newspaper to the world of our journal, Journal of environmental health, Vol. 71. no. 9; pp. 61-62. May 2009..

Ford., M.,W, (2000). Size, Structure and Change Implementation., An empirical comparison of small and large Organizations., Management Research News Vol. 32 No. 4, 2009 .,pp. 303-320.

Gerum., E., and Stieglitz., N (2005) ., Corporate Governance, Ownership Structures, and Corporate Strategy Mediia Companies: The German Experience., Corporate Governance of Media Companies., Media Management and Transformation Centre Jönköping 
International Business School., page 127.

Hamaker, J.L., (2009) , Information Technology Investment Methodologies; An Investigation Into method/Technology Fit., A Dissertation., The Graduate College at the University of Nebraska.

Harrigan, K.R., (1980)., Strategy Formulation in Declining Industries., Academy of Management, The Academy of Management Review., Oct 1980., vol. 5 no. 4, pp. 599-604.

Hatch., M.J. and Cunliffe., A., L., (2006) Organization Theory, Modern, Symbolic, and Postmodern Perspectives., Second Edition., Oxford Univeristy Press., 2006

Lowrey., W.(2003)., Explaining Variability in Newspaper Design: An Examination of The Role of Newsroom Subgroups., Journalism and Mass Communication Quarterly; Summer 2003; 80.2. ABI/INFORM Global; pp. 348

Nayak., P.,R., (2009) .,A Study of Outsourcing of Premedia Services to India by US Companies., A Thesis ., in the School of Print Media., in the College of Imaging Arts and Sciences of the Rochester Institute of Technology.

O’Shannassy., T., (2008)., Sustainable Competitive Advantage or Temporary Competitive Advantage Improving Understanding of an Important Strategy Construct., Journal of Strategy and Management Vol. 1 No. 2, 2008.,pp. 168-180.

Picard, R, G. (2004)., Commercialism and Newspaper Quality., Newspaper Research Journal., Winter 2004., 25. pp. $54-65$.

Picard., R,G. (2005) ., Corporate Governance: Issues and Challenges., Corporate Governance of Media Companies., Media Management and Transformation Centre Jönköping International Business School., page 1.

Porter, M.E. (1980) ., Competitive Strategy, techniques for analyzing industries and competitors., The Free Press.
---------., (1998)., On Competition., A Harvard Business Review book., 1998.

Romano, F. J. (2004). An Investigation into Printing Industry Trends (Monograph No. PICRM-2004-05). Rochester, NY: Rochester Institute of Technology, Printing Industry Center.

Sherburne, C. (2006,). The art of outsourcing [Special section].Printing News, 157(14), 1,6.

Sterling, John (2008); A plan for a US newspaper industry counterattack against disruptive innovators, Strategy and Leadership Journal, vol. 36. no.1. 2008.

Sylvie., G., (2008)., Developing an Online Newspaper Business Model; Long Distances Meets The long Tail., SSchool of Journalism., the University of Texas March 24, 2008.

Victor.,P and Franckeiss., A., (2002)., The Five dimensions of Change ; an integrated approach to strategic organization., Strategic change., Jan/Feb 2002.; 11.1., ABI/INFORM GLOBAL pp. 35. 